\title{
Cell autofluorescence and lipofuscin
}

\author{
Giovanni Di Guardo* \\ Faculty of Veterinary Medicine, University of Teramo, Teramo, Italy \\ *Correspondence: gdiguardo@unite.it \\ Edited by: \\ Achim Weber, University of Zurich, Switzerland \\ Reviewed by: \\ Giuseppe Borzacchiello, Università degli Studi di Napoli Federico II, Italy
}

Keywords: autofluorescence, lipofuscin, lipofuscin-like substances, stem cells, epithelial cancer stem cells, cancer stem cells

\section{A commentary on}

Intracellular autofluorescence: a biomarker for epithelial cancer stem cells by Miranda-Lorenzo I, Dorado J, Lonardo E, Alcala S, Serrano AG, Clausell-Tormos J, et al. Nat Methods (2014) 11:1161-69. doi:10.1038/nmeth.3112

I was greatly impressed by an article recently published in Nature Methods (1), in which intracellular autofluorescence was characterized as a biomarker for epithelial cancer stem cells (CSCs). Interestingly, this epithelial CSC-specific autofluorescence was also associated with a highly invasive and chemoresistant phenotype. Riboflavin (vitamin $\mathrm{B}_{2}$ ) - an ABCG2-selectively transported substrate - was identified, after autophagy had been ruled out, as the source of cell autofluorescence (1).

I have concerns about the fact lipofuscin was not included by the aforementioned authors among the putative causes of epithelial CSC autofluorescence. In this respect, it is worth mentioning that autofluorescent lipofuscin-like pigments have been reported to decrease, following differentiation, in murine embryonic stem cells (2). Furthermore, lipofuscin bodies, which are well-known markers for both aging and senescent cells, may be easily demonstrated, apart from autofluorescence, by means of Schmorl or Sudan Black histochemical stains (3). It should be additionally emphasized that lipofuscin bodies may occur in a variety of neoplasias, such as pancreatic tumors (4) and non-choroidal melanomas (5), with their number increasing in cell cultures from invasive mammary gland carcinomas (3).

As previously mentioned, autophagy was excluded as a possible source of epithelial CSC-specific autofluorescence (1). In this respect, it is also worth mentioning that the "macroautophagic system," the best characterized among autophagyrelated pathways (6), has been recently found to be hampered in aging by intracellular lipofuscin accumulation (7).

On the basis of what above, while the practical relevance and implications of the original findings by Dr. Miranda-Lorenzo and coworkers appear to be of crucial significance from the "fight against cancer viewpoint," on one side, it should be also underscored, on the other side, that not including (or ruling out) lipofuscin and lipofuscin-like compounds among the factors responsible for epithelial CSC autofluorescence appears to be a (relevant) methodological error.

In conclusion, the potential contribution, if any, of lipofuscin and lipofuscin-like substances to the autofluorescent phenotype reported in epithelial CSCs (1) would deserve adequate consideration.

\section{REFERENCES}

1. Miranda-Lorenzo I, Dorado J, Lonardo E, Alcala S, Serrano AG, Clausell-Tormos J, et al. Intracellular autofluorescence: a biomarker for epithelial cancer stem cells. Nat Methods (2014) 11:1161-9. doi: $10.1038 /$ nmeth.3112

2. Santin G, Paulis M, Vezzoni P, Pacchiana G, Bottiroli $\mathrm{G}$, Croce AC. Autofluorescence properties of murine embryonic stem cells during spontaneous differentiation phases. Lasers Surg Med (2013) 45:597-607. doi:10.1002/lsm.22182
3. Donatello S, Hudson L, Cottell DC, Blanco A, Aurrekoetxea I, Shelly MJ, et al. An imbalance in progenitor cell populations reflects tumour progression in breast cancer primary culture models. J Exp Clin Cancer Res (2011) 30:45. doi:10.1186/1756-996630-45

4. Daum O, Sima R, Mukensnabl P, Vanecek T, Brouckova M, Benes Z, et al. Pigmented solidpseudopapillary neoplasm of the pancreas. Pathol Int (2005) 55:280-4. doi:10.1111/j.1440-1827.2005. 01825.x

5. Penouil MH, Gourhant JY, Segretin C, Weedon D, Rosendahl C. Non-choroidal yellow melanoma showing positive staining with Sudan Black consistent with the presence of lipofuscin: a case report. Dermatol Pract Concept (2014) 4:45-9. doi:10.5826/ dpc.0402a09

6. Codogno P. Shining light on autophagy. Nat Rev Mol Cell Biol (2014) 15:153. doi:10.1038/nrm3751

7. Ureshino RP, Rocha KK, Lopes GS, Bincoletto C, Smaili SS. Calcium signaling alterations, oxidative stress, and autophagy in aging. Antioxid Redox Signal (2014) 21:123-37. doi:10.1089/ars.2013.5777

Conflict of Interest Statement: The author declares that the research was conducted in the absence of any commercial or financial relationships that could be construed as a potential conflict of interest.

Received: 07 January 2015; paper pending published: 04 February 2015; accepted: 06 February 2015; published online: 19 February 2015.

Citation: Di Guardo G (2015) Cell autofluorescence and lipofuscin. Front. Med. 2:6. doi: 10.3389/fmed.2015.00006

This article was submitted to Pathology, a section of the journal Frontiers in Medicine.

Copyright (c) 2015 Di Guardo. This is an open-access article distributed under the terms of the Creative Commons Attribution License (CC BY). The use, distribution or reproduction in other forums is permitted, provided the original author(s) or licensor are credited and that the original publication in this journal is cited, in accordance with accepted academic practice. No use, distribution or reproduction is permitted which does not comply with these terms. 